\title{
EVOLUTION OF INQUIRY QUESTIONS IN A CYCLIC PROFESSIONAL DEVELOPMENT PROGRAM
}

\author{
John Gruver \\ Michigan Technological University \\ Janet Bowers \\ San Diego State University
}

\begin{abstract}
Teachers in professional development (PD) programs need time to adopt, enact and reflect on what they are learning in the PD within their own situations. To encourage reflective implementation and adaptation of ideas and practices promoted in the PD studied in this article, participants were asked to engage in several small action research projects over time. To gain insights into how the cyclic process of implementation and reflection effected changes in practice and knowledge, we examined the nature of the research questions asked by a cohort of teacherresearchers ( $n=31)$ as they engaged in several cycles of action research over a threeyear period. We found the nature of the questions they asked shifted over time from investigating the efficacy of particular interventions in terms of students' performance to exploring how to support students as they reason about mathematics. These results provoke questions about why these particular changes occurred and why others did not.
\end{abstract}

KeY WoRDS: Professional development; Teacher inquiry; Action research

\section{INTRODUCTION}

One of the characteristics of effective professional development (PD) programs is that they take place over time to provide repeated opportunities for teachers to implement and reflect on the strategies they learn (e.g. Darling-Hammond, Hyler, Gardner, 2017; Garet, Porter, Desimone, Birman, \& Yoon, 2001; Knapp, 2003). These reports have defined effective PD programs in terms of outcomes-either changes in teachers' knowledge or practice, or improvements in student learning. Our goal is to take a closer look at one of the mechanisms that cause these changes, teacher inquiry (Adler, Ball, Krainer, Lin, \& Novotna, 2005; Jaworski, 2006). In 
particular, we examined the evolution of the types of questions one cohort of K-8 teachers asked over time as they engaged in a particular type of inquiry, action research. This gave insight into what teachers attended to as they engaged in the inquiry process. We found that as teachers engaged more in the PD sessions and became more deeply steeped in the process of action research, they asked more profound questions that moved from a focus on the effect of specific interventions to proffering causal relations between teaching practices and student reasoning.

\section{Changes that Result From Action Research}

For the purposes of this report, we use Kemmis and McTaggart's (2005) definition of classroom action research (AR) as "qualitative interpretive modes of inquiry and data collection by teachers (often with help from academics) with a view to teachers making judgments about how to improve their own practices" (p. 561). This definition does not necessarily imply that the process is cyclic, although in our view, AR is most productive when teachers refine or even change their questions over time.

\section{Changes in Practice}

There are several reasons that researchers believe teachers change their practice when engaging in AR. First, by being engaged in analysis, comparing analyses, and communicating their work, teachers are directing their own inquiries and developing a deeper awareness of their practice and how it influences learning (Gilles, Wilson, \& Elias, 2010; Potari, Sakonidis, Chatzigoula, \& Manaridis, 2010). A second reason that AR leads to changes in practice is that the act of writing, and ultimately sharing, provides an opportunity for teachers to organize and articulate their thoughts within the context of a supportive group of colleagues who value this work. Discussion and acceptance among peers is a powerful motivator for changing teachers' views of their work and the subjects they teach. For these reasons, engaging in action research, and reporting the results, is a viable and valuable research genre that can stimulate reflection and thereby offer a great deal of authenticity and contextual relevance for otherwise seemingly disjoint theories of learning (Johnson \& Golombek, 2002; Price, 2001).

While most teachers engage in reflection on their practice to some degree in their day to day work, action research promotes deeper, more methodical reflection on the details of their work (O'Sullivan, 2002). A myriad of studies have documented the success of this deeper engagement in affecting change in teachers' practice (Edwards \& Hensien, 1999; Johnson \& Golombek, 2002; Perrin-Glorian, Deblois, \& Robert, 2008; Raymond \& Leinenbach, 2000; Slavit \& Nelson, 2009). The majority of these reports present case studies of particular teachers undergoing an AR project (Ado, 2013; Bonner, 2006; Cochran-Smith, Barnatt, Friedman, \& Pine, 2009; Edwards \& Hensien, 1999; Raymond \& Leinenbach, 2000). By documenting the changes made by particular teachers, the researcher gains insights into how a teacher's engagement with action research supported changes in practice, views of learning and teaching, or both. For example, Edwards and Hensien (1999) described how the collaboration between a mathematics teacher educator and the teacher-research supported the teacher-research's examination of her own beliefs and practices, catalysing change as she engaged in the AR process. 


\section{Changes in Orientation}

Other studies have emphasized the effects of action research on teachers' thinking about and orientation towards teaching and, ultimately, their identities. For example, Bonner (2006) interviewed two teachers and analysed their reflective journals, classroom artefacts, field notes from researcher observations, and research meeting notes throughout the action research process. She found that in addition to changing their practice, the two teachers in her study developed a better attitude toward math instruction, had more confidence in teaching mathematics, and developed a greater appreciation of student thinking and potential. Similarly, other scholars have reported that teachers gain a deeper commitment to improving their practice (Bruce Flynn, \& Stagg-Peterson, 2011; Price, 2001).

One explanation for the profound changes in orientation that can result from AR is that deep reflective engagement affects teachers' identities. For example, Hulse and Hulme (2012) report that AR can help teachers, especially novice teachers, develop powerful professional identities because they learn to assert agency within their world. They see change and feel that they have had a profound effect on a student, which, in turn, affects them as well. Other reports suggest that as teachers adopt inquiry as a way of being, they can contribute to a culture of inquiry in the school (Gilles et al., 2010; Jaworski, 2008).

\section{Multiple Cycles of Action Research}

Given the positive outcomes of AR cited in the literature, one might assume that these outcomes would simply compound over multiple cycles of AR. However, there is some concern that teachers can also use AR to confirm their own hypotheses (see the case of Marilyn in Raymond \& Leinenbach, 2000). McCutcheon and Jung (1990) argued that teachers have personal, perhaps implicit, theories of teaching that influence what questions they ask and how they collect and analyse data as they perform action research. Their questions and methods then influence what they are positioned to learn (Cochran-Smith et al., 2009). This suggests that for some teachers, multiple cycles of action research might not have a transformative effective on their practice, but rather further immerse them in their original perspectives.

Conversely, there is also evidence that AR itself can broaden what teachers notice and thereby help them adjust their perspective on the teaching and learning process. For example, Price and Valli (2005) reported the experience of a preservice teacher candidate, Irene, who conducted an action research project while student teaching that helped her appreciate the complexity of assessing student understanding. Irene was surprised by her students' poor performance on an exam since it did not match her expectation of her students' understanding based on their contributions to class discussions. As a result, she decided to systematically investigate this disconnect. This helped her better understand her students' understandings and how to build on their contributions in her instruction. Her reflection indicated a new awareness of the importance of listening more carefully to individual students and relying less on whole class discussions to gauge student 
understanding. Her project not only seemed to affect her future practice, but also indicated a shift in her thinking about the teaching and learning process itself.

These differing results from AR research (self-confirming versus a broadening of perspective) motivated our desire to embed the AR projects within a PD program. We respected the autonomy and professionalism of the teachers by encouraging them to ask research questions in their AR projects that would be most helpful to them. At the same time, we were also able to expose them to new ideas and challenge some of their assumptions through the PD program. We hoped that the combination of the reflection required by $A R$ and the influence of the PD program would encourage them to investigate more nuanced issues of teaching and learning over time, resulting in meaningful personal learning and change. This gave rise to the current research, which investigates the nature of the research questions these teachers asked and how they changed over multiple cycles of AR.

\section{SetTing And Data Analysis}

The setting for this study was a three-year (2011-2014) teacher PD program that involved a collaboration between two neighbouring school districts in southern California in the United States of America and mathematics education faculty from a local university. In one district, the majority of students were emergent bilingual students, with their first language being Spanish. The student population of the other district was quite varied because of the large number of "newcomers," students from other countries who were seeking refuge in the United States. Given these populations, one of the critical foci for the PD was to support teachers' efforts to incorporate proven strategies that support emergent bilingual students.

The work was funded by the California Department of Education, which set up the California Math and Science Partnership (CaMSP) grant program. Our project was one of several distributed around the state to explore various PD models, and our project was the only one focused specifically on teacher inquiry though action research. Other models focused on approaches such as Japanese Lesson Study and online PD. The overall goal of the grant program was to conduct a large scale meta-analysis across several controlled experiments to test the efficacy of various models for PD by holding some parameters constant among all programs during a given funding cycle while allowing other variables, such as prevailing aims, to vary. During the 2011-2014 cycle, the non-negotiable parameters included: (1) a strong partnership between the Local Educational Agency (LEA) and a university mathematics or science education instructional team (Institute for Higher Education); (2) teacher retention in the program for three years with no new teacher integration, (3) a minimum of 60 hours of intensive workshop instruction and 24 hours of on-site support, and (4) a controlled scientific study such that all teachers got the same PD interventions without grade distinctions.

\section{Organization of the Professional Development Program}

At the start of the program, there were 52 teachers ranging from generalists teaching grades 3-6 to specialists teaching only mathematics in grades 6-8. The overlap in grade 6 occurred because $6^{\text {th }}$ grade was considered part of the elementary system in one district and part of the middle school in the other. Due to natural attrition and teacher re-districting, a total of 31 participants remained in 
the program for the full three years. To meet the 24 hours of on-site support, our program provided coaches (all of whom were district math specialists) who were assigned to each participant. The coaches met with their mentees at least six hours per cycle, usually before an observation, during an observation, and then for a debrief session. The "intensive" instruction was implemented in the form of faceto-face workshops that spanned 6 days each summer and 3 days during each winter. While the scheduling of these was mandated by parameter \#3 (listed above), it was parameter \#4, providing the exact same treatment to all participants, that turned out to be one of the most influential aspects of the program. While we, as instructors, often lobbied the director to allow us to break into grade-level groups, the director maintained fidelity to the program requirements and her own beliefs that cross-grade discussions were valuable for promoting teachers' exchanges of perspective. Her intuition turned out to be insightful and fortuitous: cross grade discussions enabled ideas to spread across landscapes of influence and led to idea development.

The curriculum for this program included readings and discussions focusing both on how to specifically support emergent bilingual learners (Echevarria, Richards, Canges, \& Francis, 2011) and how to support students more generally (National Governors Association Center for Best Practices \& Council of Chief State School Officers, 2010; Smith \& Stein, 2011). We also discussed research on ways to teach specific topics, such as multiplication of fractions using manipulatives (Bezuk, Cathcart, Pothier, \& Vance, 2011), and rational number models, such as placing fractions on a clothesline to simulate ordering quantities on a number line (Bay, 2001).

Each teacher participant was asked to conduct at least one AR project during the fall semester and one during each spring. The teachers were free to choose their own questions or pursue an idea discussed in a workshop. The projects were conducted in the participants' own classrooms and they were asked to submit a narrative to their coaches describing their question, methods, and results. In order to introduce the idea of framing a research question, each cycle we invited an educational researcher from the university to discuss his or her method for identifying a question, operationalizing a method for investigating it, and then collecting some data to support or refute a prevailing hypothesis.

Upon returning from their Spring or Fall AR projects, each participant was asked to present an inquiry narrative to the group. This was conducted through a series of poster sessions that involved having participants, instructors, administrators, and visitors peruse the posters and discuss the outcomes with the teachers. These freeflowing interchanges enabled participants to reflect on their own inquiry narratives as recommended by Johnson \& Golombek (2002), and enabled instructors to see which interventions seemed to be of most use to the participants. The poster sessions also elevated the quality of the work that the teachers did because they could now recognize the value of their work as a viable genre for educational research. 


\section{Data Analysis Procedures}

Qualitative data coding and analysis involved identifying themes in AR projects that emerged over time. In order to avoid being influenced by participant identity or time frame during which the inquiry was conducted, a team of three coders independently sorted the AR project titles (stripped of any name or time delimiters) that the participants submitted each cycle. Because the participants were asked to structure their project titles in a very specific form, (i.e. "If intervention, then target assessment") the researchers focused their coding on two dimensions: (a) the nature of the intervention, and (b) the nature of the target assessment. For example, consider an inquiry such as, "If I use fraction circles to model addition, then $75 \%$ of my students will be able to explain fraction addition." The intervention is the use of fraction circles, and the target assessment is that $75 \%$ of students will be able to explain their thinking. Using axial coding (Strauss \& Corbin, 1990) we identified six categories of interventions:

- GRP: Grouping strategies (e.g., directing students to collaborate using specified models such as partners).

- MANIP: Use of manipulatives or models (e.g., fraction circles or number lines).

- ORG: Use of organizational strategies (e.g., use of instructional supports for emergent bilingual students, such as Frayer models, starter sentences, etc.).

- RWPs: Real world problems or use of "messy" or multi-step problems.

- VOCAB: Use of correct mathematical vocabulary (i.e., Common Core State Standards mathematical practices \#3 and \#6, using precision and correct vocabulary to communicate about mathematical ideas effectively).

The second dimension, the assessment target, was coded according to their depth of expected knowledge (Webb, Alt, Ely, \& Vesperman, 2012) or cognitive demand (Boston \& Smith, 2009, 2011). Using a coding scheme adapted from these two categorical systems, we assigned three target levels as follows:

- Level 1: Targeting skill mastery. Questions at this level usually involved setting a certain percentage of students who would score at a proficient level on some calculational task such as multiplying fractions.

- Level 2: Targeting increased proficiency in providing in-depth student explanations that extended beyond simple numerical answers.

- Level 3: Targeting a goal of having all students either engage in multiple solution methods or justify their answers in small groups and critique others' explanations as well.

\section{RESULTS}

Participation in the PD led to statistically significant teacher change both in terms of content knowledge ${ }^{1}$ and teaching practices $^{2}$. Due to California's transition from

\footnotetext{
${ }^{1}$ As measured by the Learning Mathematics for Teaching assessment (Hill, Schilling, \& Ball, 2004).
} 
the traditional tests to the Smarter Balanced Assessment Consortium, we were unable to track changes in students' performance on standardized measures of mathematical performance. In what follows, we explore the mechanisms that were involved in these significant shifts by focusing on both the shifts in what the teachers were examining (i.e., their targets) and the shifts in the types of interventions they were enacting.

Results of the blinded coding of the AR projects enabled us to document how the teachers' foci shifted over the course of the three-year program. Figure 1 shows participants' shifts in target levels over time. During the first round of inquiry, $80 \%$ of the teachers' AR projects focused on studying outcomes in terms of student mastery (Level 1). This makes sense because the participants were accustomed to the district-driven performance outcomes where a given percentage of students were expected to perform at a passing rate. The results from cycle 2 indicated that a significant number of the AR projects shifted from mastery to expecting students to explain their thinking and some even promoting level 3 assessment. During cycle 3, all teachers moved away from mastery and focused either on having students explain their thinking on a given task (Level 2) or work collaboratively and critique the reasoning of others (Level 3).

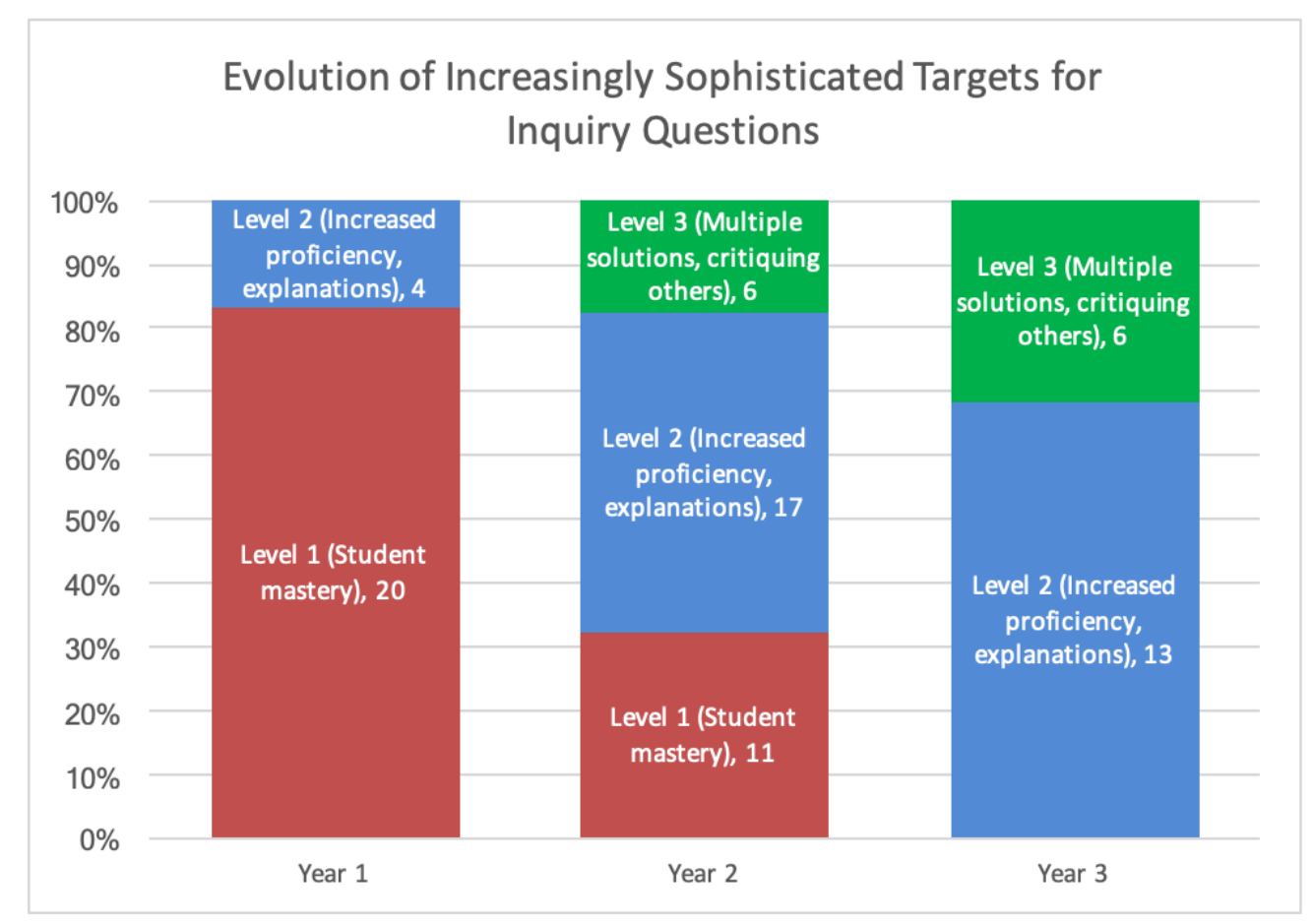

Figure 1. Changes in Target Levels over Three Years

We also investigated whether there was a connection between the target levels and the practices the teachers were studying in the workshops. For instance, we noted that most questions posed during the first cycle relied on the use of

\footnotetext{
2 As measured by the Sheltered Instruction Observation Protocol (Echevarria, Richards, Canges, \& Francis, 2011; Echevarria, Richards-Tutor, \& Chinn, 2011).
} 
manipulatives and tended to focus on lower level target goals, such as skill mastery. Figure 2 shows which interventions were most often posed during each cycle. ${ }^{3}$

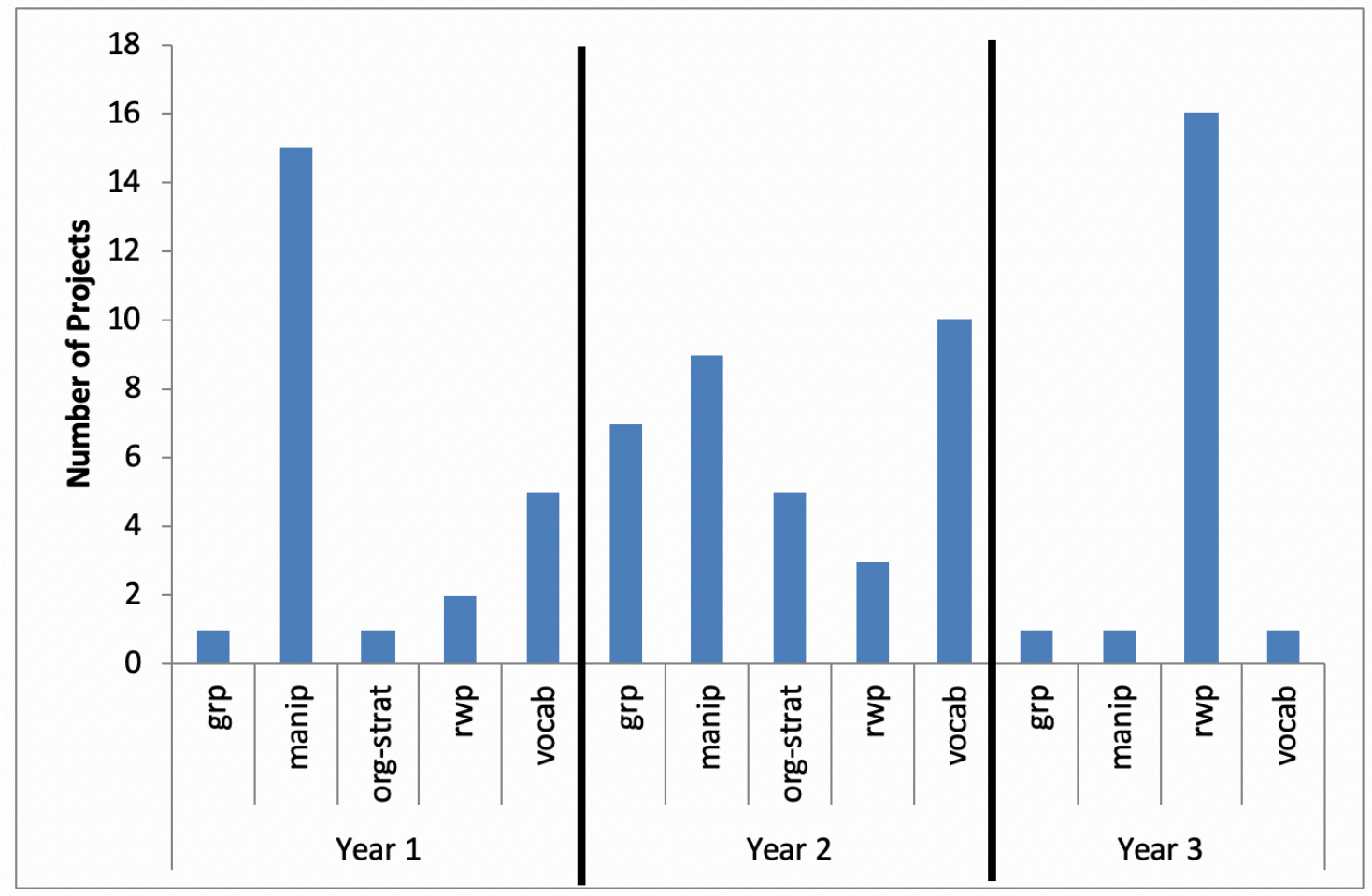

Figure 2. Count of different inquiry project interventions by year.

Figure 2 indicates that the majority of teachers focused on manipulatives as the main intervention in year 1 and real-world problems in year 3. However, there were a variety of different interventions posed in year 2 , which suggests that this was when many participants were searching for answers by focusing on a variety of different social interventions such as organizational strategies, vocabulary lists, and group work to focus their inquiries.

In order to examine the question of association between the level of target outcomes and the interventions, we developed Figure 3, which combines Figures 1 and 2. As Figure 3 indicates, many of the teachers asked assessment level 1 questions when targeting students' use of manipulatives and appropriate vocabulary. In contrast, they seemed to ask higher assessment level questions when they focused on more open-ended interventions, such as the use of student groups and real-world problems.

The coding of the action research questions also revealed some interesting patterns about how the teachers chose their topics. Most teachers (70\%) not only

\footnotetext{
3 The number of inquiry projects is not consistent across the three cycles because some teachers chose to continue an inquiry project from a prior cycle and other teachers chose to collaborate on a project during various points in the program.
} 
increased the complexity of the assessment level over time, but also changed the type of intervention they wanted to study. For example, consider fourth-grade teacher Roxanne's ${ }^{4}$ shift. In cycle 1 her research question was, "If I teach and model a repeated subtraction model of division that involves the multiplication of only known facts, then all students will be more successful at dividing greater numbers by one digit with place value." In contrast, she shifted her intervention and target assessment level in cycle 3 to, "If I plan and use structured participation activities to provide every student the opportunity to talk and I plan response starters/frames and question starter/frames, then all students will be able to explain their thought processes and respond to others." This shift indicates that her orientation toward research moved from asking how one teaching intervention (subtraction model for division) would affect test scores to the much more ambitious question of how supporting shifts in her own classroom's collective ways of talking with each other would affect their individual practices of explaining their answers.

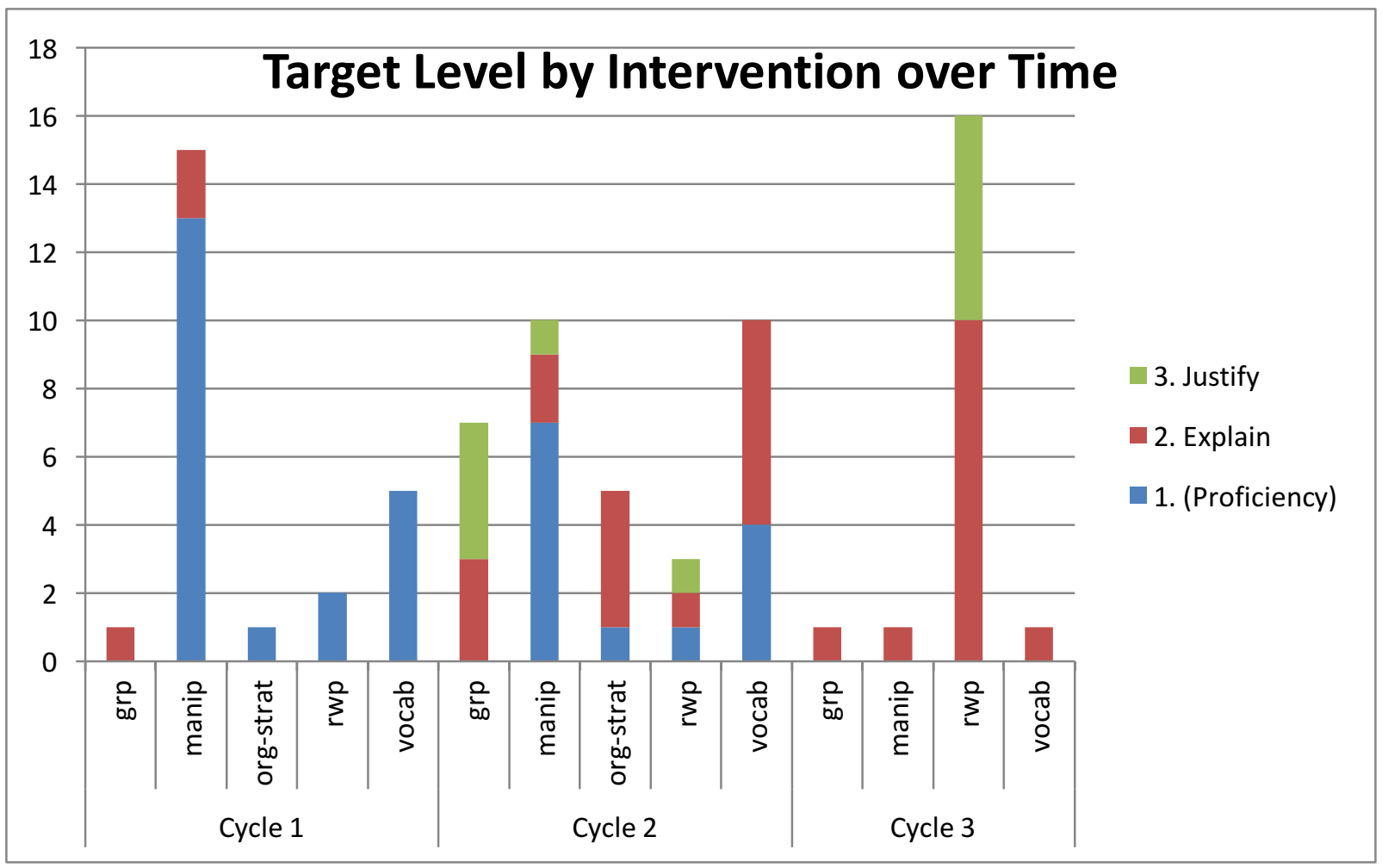

Figure 3. Combined intervention and target assessment levels over time.

The remaining $30 \%$ of participants kept a constant focus on one intervention, but also shifted the target level outcomes. For example, Juan, a 7 th grade teacher, asked the following inquiry question during cycle 1, "If I use manipulatives to show students how to solve multiplication of fractions problems, then $75 \%$ of my students will be proficient." During cycle 3, he remained committed to the content of fraction multiplication, but asked, "If I use questioning to encourage students to

\footnotetext{
${ }^{4}$ All participants were given pseudonyms during coding and analysis.
} 
defend and justify their answers, they will be able to represent fraction operations with manipulatives and demonstrate/explain how the products are different". In this case, the teacher remained focused on the same topic and intervention (fraction multiplication modelled with manipulatives), but shifted his focus of assessment from mastery to student explanations.

\section{Discussion}

The goal of this research has been to examine one potential mechanism to explain the shifts in teachers' practices and the deepening of their content knowledge. Namely, we examined the evolution in the nature of teachers' inquiry, in terms of the research questions they asked as they performed AR projects. The main trend that we identified was that teachers shifted from asking research questions focusing on single-shot remedies such as manipulatives toward a focus on multiple, coordinated interventions that aimed to support students' propensity to offer explanations and peer-to-peer argumentation. We see these changes as significant and productive. We have argued that one reason for the effectiveness of $\mathrm{AR}$ is the deep reflection it promotes as teachers examine their own practice. We see the nature of the questions teachers ask as influencing how they examine their practice and mediating what they are positioned to learn as they engage in action research and concomitant reflection. If asking a relatively straightforward question about how manipulatives would affect test scores revealed some of the nuances of teaching and learning, how much more would be revealed when a question about how increasing the cognitive demand of questions could support students' ability to provide appropriate justifications was asked? The types of questions teachers asked at the end of the PD positioned the teachers to learn about the nature of student reasoning and to examine the nature of their classroom discourse. However, we also noticed that other types of questions were not asked. In particular, even though many of the students were emergent bilingual students of diverse backgrounds, these aspects of students' identities, while acknowledged in some questions, did not seem to be the focus of most questions.

These results naturally raise questions of why these changes (and not others) occurred. In particular, it seems that over time the questions became more nuanced and deeper (e.g. moving from a focus on increasing test scores to seeing competence as being able to explain your reasoning), but at the same time coalescing around a particular type of question (e.g. the effects of using real world problems). While we cannot definitely determine the causes of this change, we offer two hypotheses that raise considerations for both teacher-researchers doing action research and teacher educators who work with them.

The first hypothesis stems from the idea that projects in early cycles may have changed the teachers' view of teaching and learning. From previous research, we know that the processes inherent to action research promote deep reflection by the teacher-researchers on their practice. Other researchers have linked this reflection to changes in teaching practice, but this reflection is also a plausible explanation for the changes in research focus. As teacher-researchers begin to notice subtleties in the teaching-learning process as it occurs in her classroom, this naturally leads to changes in instruction, as well as an ability to ask more nuanced 
research questions. As teachers learned from previous AR projects and the professional development intensives, they began to consider more complex interventions and ways of assessing the efficacy of those interventions. This can help explain the deepening of teachers' questions.

The second hypothesis is that both emergent norms for engaging in research and the PD leaders' values influenced participants' questions. This can help explain why questions coalesced around a particular type. We are influenced by Cobb and colleagues' emergent perspective for analysing young children's participation in mathematics classrooms (Bowers, Cobb, \& McClain, 1999; Cobb \& Bowers, 1999; Cobb \& Yackel, 1996) to frame observations of the reciprocity between how individual ways of participating in inquiry were related to the collective norms for participation. The underlying assumption of this perspective is that individual and collective growth are reflexively related. On the one hand, the differing ways that individuals participate in the various activities affect the practices that become negotiated to be normative. On the other hand, the ways in which individuals perceive the collective norms affect the ways that he or she participates. In the present study, this perspective would suggest that norms for participating in the PD, including those for doing action research (e.g. what types of questions are acceptable to ask and how to analyse and report data), would be negotiated as individual teacher-researchers participated in the PD. These norms would then influence how the teacher-researchers participated in the PD going forward, including determining the focus of their next inquiry project.

At the group level, the community of teacher-researchers likely supported changes in how teachers engaged in AR, particularly in terms of the questions they asked, because teachers were learning new ways of thinking about mathematics and sharing their efforts to initiate these changes in their classes. For example, in the winter of cycle 1, one of the PD instructors introduced an example of a student's non-conventional approach for adding fractions. When the instructor asked for reactions to the student's answer, the overall response was one of concern about how this child would be assessed on a standardized test. In year 3, the same instructor posed a similar question with slightly different but equally novel student response. This time, the teachers engaged in very different reflections, and the norms for doing so had changed to support these different reactions. One teacher noted that the student's work demonstrated the equivalence of fractions. Another suggested that the child had constructed some imagery associated with partitioning. A third teacher wondered if the student might have been drawing on prior real-life experiences. Taken together, these teachers' collective reaction illustrates a qualitative shift from a focus on "Is this answer correct?" to a focus on "What does this child understand?" This is consistent with a greater appreciation of the complexity of student understanding and its nuances. The emergent perspective would suggest this shift in norms regarding the analysis of student work reinforced and supported the shift in focus of individual inquiry projects.

A second aspect of the social dynamics that may have affected the nature of the teachers' questions was the focus and values of the PD instructors. Even though the teacher educators leading the PD did not directly discuss what the teachers 
should focus on in their inquiry projects, the ways in which they interacted with teachers during the PD likely communicated their values. For example, after the vignette presented above occurred in which the teachers focused on how the student would be marked on an exam, the PD instructor tried to refocus their attention on what the child understood. This underscores the point that there were PD instructors actively trying to get the teachers to attend to specific things, such as student thinking. This focus on student thinking was typical and can help explain both why teachers' questions eventually went beyond test scores and also why teachers' questions tended to focus on individual understanding rather than the social contexts of learning.

Furthermore, it is important to note that the teacher-researchers were exposed to educational research in the professional development sessions. This may have inspired topics to research, but may have also cued them the types of questions that are typically asked in the educational research community. This hypothesis has some support from the data. For example, looking at Figure 3, we can see that the majority of participants chose to focus on the use of manipulatives during cycle 1 , which aligns with the PD focus during that cycle.

\section{Closing Remarks}

This study adds to the discussion of well-documented view that it takes time for professional development to change teachers' practice and orientation (LoucksHorsley, Stiles, Mundry, Love, \& Hewson, 2010). We documented the nature of this change over time with respect to the aspects of teaching and learning that teachers attended to as they developed research questions over several iterations of AR. We see the changes that occurred in this study as encouraging, but they also raise important considerations. On the one hand, the collective nature of the PD encouraged the teachers to deepen their inquiry questions over time. However, we also think it is worth reflecting on how to avoid becoming overly focused on a single aspect of teaching over several cycles of inquiry. In our case, while we tried to offer strategies for supporting emergent bilingual students in mathematics classrooms, it appears we more clearly communicated ideas about conceptual understanding of mathematics, the importance of cognitively demanding tasks, and the value in having students explain their reasoning. If we had the resources to continue working with these teachers, we would think more deeply about how to encourage them to also consider issues of language and culture in their research projects.

As researchers, we became aware of the focus on mathematics in teachers' research projects because we attended to the types of questions they asked. Likewise, we suggest teacher-researchers and teacher educators attend to the types of questions teacher-researchers are asking in their research. They could then reflect on who might be well positioned to offer an alternative point of view and how they might invite those people to engage with their work.

There are still many questions about how the focus of teacher-researchers' AR inquiries evolve over time. While we see it as likely that both teachers' engagement in multiple cycles of AR and the social forces of a supportive community in the PD 
affected the nature of the inquiry projects, the extent to which each aspect impacted the evolution of AR projects is not known and could an important line of future research. Understanding the nature of teacher educator support to help teachers productively investigate their own practice is important, especially if the sustainability of an AR model for PD is considered. In particular, it could be important to understand how to help teachers begin research on a productive line of inquiry, but also how to help guide their focus as they progress.

\section{REFERENCES}

Adler, J., Ball, D., Krainer, K., Lin, F.-L., \& Novotna, J. (2005). Reflections on an emerging field: Researching mathematics teacher education. Educational Studies in Mathematics, 60(3), 359-381. https://doi.org/10.1007/s10649005-5072-6

Ado, K. (2013). Action research: Professional development to help support and retain early career teachers. Educational Action Research, 21(2), 131-146. https://doi.org/10.1080/09650792.2013.789701

Bay, J. (2001). Developing number sense on the number line. Mathematics Teaching in the Middle School, 6(8), 448-450.

Bezuk, N., Cathcart, G. S., Pothier, Y. M., \& Vance, J. H. (2011). Learning mathematics in elementary and middle schools: A learner-centered approach (5th ed.). Boston: Pearson.

Bonner, P. J. (2006). Transformation of teacher attitude and approach to math instruction through collaborative action research. Teacher Education Quarterly, 33(3), 27-44.

Boston, M. D., \& Smith, M. S. (2009). Transforming secondary mathematics teaching: Increasing the cognitive demands of instructional tasks used in teachers' classrooms. Journal for Research in Mathematics Education, 40, 119-156.

Boston, M. D., \& Smith, M. S. (2011). A 'task-centric approach' to professional development: Enhancing and sustaining mathematics teachers' ability to implement cognitively challenging mathematical tasks. ZDM, 43(6-7), 965977. https://doi.org/10.1007/s11858-011-0353-2

Bowers, J., Cobb, P., \& McClain, K. (1999). The Evolution of Mathematical Practices: A Case Study. Cognition and Instruction, 17, 25-66. https://doi.org/10.1207/s1532690xci1701_2.

Bruce, C. D., Flynn, T., \& Stagg-Peterson, S. (2011). Examining what we mean by collaboration in collaborative action research: A cross-case analysis. 
Educational Action Research, 19(4), 433-452. https://doi.org/10.1080/09650792.2011.625667

Cobb, P., \& Bowers, J. (1999). Cognitive and Situated Learning Perspectives in Theory and Practice. Educational Researcher, 28(2), 415. https://doi.org/10.3102/0013189X028002004

Cobb, P., \& Yackel, E. (1996). Constructivist, emergent, and sociocultural perspectives in the context of developmental research. Educational Psychologist, 31(3), 175-190.

Cochran-Smith, M., Barnatt, J., Friedman, A., \& Pine, G. (2009). Inquiry on inquiry: Practitioner research and student learning. Action in Teacher Education, 31(2), 17-32. https://doi.org/10.1080/01626620.2009.10463515

Darling-Hammond, L., Hyler, M. E., Gardner, M. (2017). Effective teacher professional development. Palo Alto, CA: Learning Policy Institute.

Echevarria, J., Richards, C., Canges, R., \& Francis, D. (2011). Using the SIOP model to promote the acquisition of language and science concepts with English learners. Bilingual Research Journal, 34(3), 334-351.

Echevarria, J., Richards-Tutor, C., \& Chinn, V. (2011). Did they get it? The role of fidelity in improving teaching for English learners. Journal of Adolescent and Adult Literacy, 54(6), 425-434.

Edwards, T. G., \& Hensien, S. M. (1999). Changing instructional practice through action research. Journal of Mathematics Teacher Education, 2(2), 187-206.

Garet, M., Porter, A., Desimone, L., Birman, B., \& Yoon, K. S. (2001). What makes professional development effective? Results from a national sample of teachers. American Educational Research Journal, 38(4), 915-945

Gilles, C., Wilson, J., \& Elias, M. (2010). Sustaining teachers' growth and renewal through action research, induction programs, and collaboration. Teacher Education Quarterly, 37(1), 91-108.

Hill, H., Schilling, S., \& Ball, D. (2004). Developing Measures of Teachers' Mathematics Knowledge for Teaching. Elementary School Journal, 105, 1130. doi: 10.1086/428763.

Hulse, B., \& Hulme, R. (2012). Engaging with research through practitioner enquiry: The perceptions of beginning teachers on a postgraduate initial teacher education programme. Educational Action Research, 20(2), 313329. https://doi.org/10.1080/09650792.2012.676310

Jaworski, B. (2006). Theory and practice in mathematics teaching development: Critical inquiry as a mode of learning in teaching. Journal of Mathematics 
Teacher Education, 9(2), 187-211. https://doi.org/10.1007/s10857-0051223-z

Jaworski, B. (2008). Building and sustaining inquiry communities in mathematics teaching development: Teachers and didacticians in collaboration. Sense Publishers. https://dspace.lboro.ac.uk/dspace-jspui/handle/2134/8813

Johnson, K. E., \& Golombek, P. R. (2002). Teachers' narrative inquiry as professional development. Cambridge, UK: Cambridge University Press.

Kemmis, S., \& McTaggart, R. (2005). Participatory action research: Communicative action and the public sphere. In N. K. Denzin \& Y. S. Lincoln (Eds.), The Sage handbook of qualitative research (3rd ed., pp. 559-604). SAGE Publications.

Knapp, M. S. (2003). Professional development as policy pathway. Review of Research in Education, 27(1), 109-157.

Loucks-Horsley, S., Stiles, K. E., Mundry, S., Love, N., \& Hewson, P. (2010). Designing professional development for teachers of science and mathematics. Thousand Oaks, CA: Corwin.

McCutcheon, G., \& Jung, B. (1990). Alternative perspectives on action research. Theory Into Practice, 29(3), 144-151. https://doi.org/10.1080/0040 5849009543447

National Governors Association Center for Best Practices, \& Council of Chief State School Officers. (2010). Common core state standards mathematics. Washington D.C.: National Governors Association Center for Best Practices, Council of Chief State School Officers.

O'Sullivan, M. C. (2002). Action research and the transfer of reflective approaches to in-service education and training (INSET) for unqualified and underqualified primary teachers in Namibia. Teaching and Teacher Education, 18(5), 523-539.

Perrin-Glorian, J. M., Deblois, L., \& Robert, A. (2008). Individual practicing mathematics teachers. In K. Krainer \& T. Wood (Eds.), Participants in mathematics teacher education (pp. 35-61). The Netherlands: Sense Publishers.

Potari, D., Sakonidis, H., Chatzigoula, R., \& Manaridis, A. (2010). Teachers' and researchers' collaboration in analysing mathematics teaching: A context for professional reflection and development. Journal of Mathematics Teacher Education, 13(6), 473-485. https://doi.org/10.1007/s10857-010-9161-9

Price, J. N. (2001). Action research, pedagogy and change: The transformative potential of action research in pre-service teacher education. Journal of 
Curriculum Studies, 33(1), 43-74. https://doi.org/10.1080/00220 270118039

Price, J. N., \& Valli, L. (2005). Preservice teachers becoming agents of change pedagogical implications for action research. Journal of Teacher Education, 56(1), 57-72. https://doi.org/10.1177/0022487104272097

Raymond, A. M., \& Leinenbach, M. (2000). Collaborative action research on the learning and teaching of algebra: A story of one mathematics teacher's development. Educational Studies in Mathematics, 41, 283-307. https://doi.org/10.1023/A:1004091631981

Slavit, D., \& Nelson, T. H. (2009). Collaborative teacher inquiry as a tool for building theory on the development and use of rich mathematical tasks. Journal of Mathematics Teacher Education, 13(3), 201-221. https://doi.org/ 10.1007/s10857-009-9136-x

Smith, M., \& Stein, M. K. (2011). 5 Practices for orchestrating productive mathematics discussions. Reston, VA: National Council of Teachers of Mathematics.

Webb, N. L., Alt, M., Ely, R., \& Vesperman, B. (2012). Web alignment tool: Training Manual 1.1. http://www.wcer.wisc.edu/WAT/Training\%20Manual\% 202.1\%20Draft\%20091205.doc

\section{BIOGRAPHICAL NOTE:}

John Gruver is an assistant professor in the Department of Mathematical Sciences at Michigan Technological University. His research focuses on investigating both classroom discourse practices that support learners in developing sophisticated understanding of mathematical topics and how to support teachers in developing those practices.

Janet Bowers is an associate professor in the Department of Mathematics and Statistics at San Diego State University, and she is the Director of the Math and Statistics Learning Center. Her research interests focus on supporting teacher development by providing technology-enhanced learning and reflection opportunities. She is also the coordinator for the precalculus course at SDSU, and studies how students can engage with mathematics by designing active learning experiences that enable students to model real world situations. 